\title{
Design and in Vitro Evaluation Studies of Tramadol Hydrochloride Lozenzes for Treatment of Pain in Childreans
}

\author{
T. Venkateswara Rao*, N. Bhadramma, K. Kinnera \\ Department of Pharmaceutics, Bapatla college of Pharmacy, Bapatla, Andhrapradesh, India
}

Email address:

tv_rao2@yahoo.com (T. V. Rao)

\section{To cite this article:}

T. Venkateswara Rao, N. Bhadramma, K. Kinnera. Design and in Vitro Evaluation Studies of Tramadol Hydrochloride Lozenzes for Treatment of Pain in Childreans. Science Innovation. Vol. 3, No. 6, 2015, pp. 100-107. doi: 10.11648/j.si.20150306.16

\begin{abstract}
The oral route is the most preferred route of administration of drugs because of low cost of therapy, ease of administration, patient compliance and flexibility in formulation. The illness are associated with fever, head ache and body aches so to cure the above/relief from the above, there was need to adminster the drugs to the individuals but in case of pediatric patients it was difficult to administer the dosage forms like tablets, capsules, etc. In the present investigation an attempt has been made to prepare and evaluate the sugar based medicated tramadol hydrochloride hard lozenzes for pediatrics to overcome the administration. They were prepared by heating and congealing method on laboraty scale with malt syrup as base. All the formulations were subjected to various physico-chemical parameters such as hardness, friability, content uniformity, weight variation, thickness, drug content and in vitro dissolution studies. Drug-excipients compability stuidies were conducted by FT-IR spectroscopy and results revealed that no interactions were found between drug and excipients. The results of in vitro drug release studies showed that formulations F3, F6 and F9 releases the drug 96.72,95.32 and 98.66 percentage at the end of 30 mins. The hard lozenge can provide an attractive alternative formulatin in the treatment of pain in pediatric patiants.
\end{abstract}

Keywords: Tramadol Hydrochloride, Lozenges, HPMC: Hydroxy Propyl Methyl Cellulose, Na CMC: Sodium Carboxy Methyl Cellulose, MC: Methyl Cellulose

\section{Introduction}

In oral drug delivery, the mucosa of the mouth may appear to differ little from the rest of the moist lining of the gastro intestinal tract ${ }^{1,2}$. In fact, with the notable exceptions of the esophagus and uterine cervix, this tissue is remarkably different from all other mucosa of the body, and probably has more in common with skin, with which it is forms, a junction at the lips, than with the intestinal mucosa. The use of the oral mucosa for drug delivery has led to the tendency, at least in the dermatological literature, to regard oral mucosa as a highly permeable tissue. There are many dosage forms like Lozenges, tablets, inhalers, and syrups, are in markets for the treatment of the various diseases. The "Lozenges are flavoured medicated dosage forms intended to be sucked and hold in the mouth or pharynx. These preparations are commonly used for the purpose of local or systemic effect ${ }^{3 \text {, }}$ 4". Advantages of the Lozenges as dosage forms include increasing bioavailability, reduction in gastric irritation, bypass of first pass metabolism and increase in onset of action. New drug design to this area always benefit for the patient, physician and drug industry. There are several dosage forms like in the market, there is a need for more dosage forms which acts effectively and locally asa well as systemically. Oral thrush is a disorder caused by infection of the mouth due to fungus (yeast) candida albicans. In babies it may be a severe infection sometimes causing epidemics in schools by cross-infection ${ }^{5}$.

Tramadol hydrochloride tablet lozenges are flavoured medicated dosage forms intended to be sucked and hold in mouth/pharynx. The present investigation is designed to improve patient compliance and these preparations are commonly used for the purpose of local or systemic effects through the buccal mucosa. Advantages of the Lozenges ${ }^{6,7}$ as dosage forms includes increases in bioavailability, reduction in dose size, and reduces gastric irritation, bypass first pass metabolism. When it is not effectively treated, oral thrush often leads to hospitalization, limitations on 
physical activity, insomnia nights and in some cases death. The present work is aimed at preparing a formulation of Tramadol hydrochloride Lollipops ${ }^{8,9}$ to provide prolonged retention time upto $30 \mathrm{~min}$. In oral cavity for relief of oral thrush as conventional form of lozenges retention time being around 7 mins.

\section{Materials}

Tramadol hydrochloride, a sample from hetero pharmaceuticals,HPMC3000 cps from Fisher scientific products, Mumbai, Na CMC from fisher scientific products, Mumbai, methyl cellulose from $\mathrm{S} d$ fine chem. limited, Mumbai, citric acid from yarrow chem. Products, Mumbai, calcium carbonate from yarrow chem. Products. Mumbai, menthol from yarrow chem. Products. Mumbai, sucrose from local market bapatla, Liquid glucose from rajyalakshmi enterprises, Hyderabad.

\section{Methods}

\subsection{Preformulation Studies}

The following pre formulation studies were investigated before commencement of the research work.

\subsection{Drug-Excipient Compatibility Studies}

The compatibility between tramadol hydrochloride and polymer used in the present study was carried out by FT-IR spectrophotometer. The spectrum was recorded in the wawelength region of $4000-400 \mathrm{~cm}$. the spectra obtained for tramadol hydrochloride, HPMC, Na CMC, Methyl cellulose and the physical mixture of the drug and polymers were recorded.

\subsection{Preparation of Tramadol Hydrochloride Hard Lozenges}

Tramadol hydrochloride hard lozenges are prepared in laboratory scale by heating and congealing technique ${ }^{8,9}$, the composition as given in table no1. Required quantity of malt syrup and sucrose are transferred into a copper bowl, and then heated in a heating mantle at $150^{\circ} \mathrm{C}$ for 15 minutes. Then the temperature of the mixture was brought into $90^{\circ} \mathrm{C}$, then polymers (HPMC, Na CMC, MC) Drug, flavor, calcium carbonate were added with stirring by using glass rod, and the solution was transferred into a lubricated mould. It was allowed to cool for solidification then lozenges were collected and packed in a aluminum foil.

Table 1. The composition of tramadol hydrochloride hard lozenges.

\begin{tabular}{|c|c|c|c|c|c|c|c|c|c|c|}
\hline \multirow{2}{*}{ S. no } & \multirow{2}{*}{ Ingredients(mg) } & \multicolumn{9}{|c|}{ Formulations } \\
\hline & & F1 & F2 & F3 & F4 & F5 & F6 & F7 & F8 & F9 \\
\hline 1 & Tramadol $\mathrm{HCl}$ & 23 & 23 & 23 & 23 & 23 & 23 & 23 & 23 & 23 \\
\hline 2 & HPMC-3000cps & 100 & 300 & 500 & - & - & - & - & - & - \\
\hline 3 & Sodium CMC & _- & _- & _- & 100 & 300 & 500 & _- & _- & _- \\
\hline 4 & Methyl cellulose & - & - & - & - & - & - & 100 & 300 & 500 \\
\hline 5 & Citric acid & 50 & 50 & 50 & 50 & 50 & 50 & 50 & 50 & 50 \\
\hline 6 & Calcium carbonate & 5 & 5 & 5 & 5 & 5 & 5 & 5 & 5 & 5 \\
\hline 7 & Menthol & 50 & 50 & 50 & 50 & 50 & 50 & 50 & 50 & 50 \\
\hline 8 & Sucrose & 2000 & 2000 & 2000 & 2000 & 2000 & 2000 & 2000 & 2000 & 2000 \\
\hline 9 & Malt syrup & 1772 & 1572 & 1372 & 1772 & 1572 & 1372 & 1772 & 1572 & 1372 \\
\hline
\end{tabular}

Each lozenge weighs 4 gms.

\subsection{Evaluation Parameters of Tramadol Hydrochloride Lozenges}

The formulated lozenges were evaluated for the following parameters $^{10,11}$.

Thickness

The thickness and diameter of the formulated lozenges were measured by using Vernier calipers.

Weight variation

The formulated lozenges were tested for weight uniformity. 20 tablets were collectively and individually weighed. From the collective weight, average weight was calculated. Each lozenge weight was then compared with average weight to ascertain whether it is within permissible limits or not.

$$
\% \text { Weight Variation }=\frac{\text { Average weight-Individual weight }}{\text { Average weight }} \times 100
$$

Hardness
The lozenge crushing strength, which is the force required to break the lozenge by compressionin the diametric direction was measured in triplicate using Pfizer tablet hardness tester.

Friability:

The Roche friability test apparatus was used to determine the friability of the lozenges. 5 pre weighed lozenges were placed in the apparatus, which was subjected to 100 revolutions. Then the lozenges were reweighed. The percentage friability was calculated by using the formula.

$$
\% \text { Friability }=\frac{\text { Initial Weight- Final Weight }}{\text { Initial weight }} \times 100
$$

Drug content

Lozenges were weighed and powdered. The quantity of powder equivalent to $100 \mathrm{mg}$ of was dissolved in buffer diluted to $100 \mathrm{ml}$ with buffer then the solution was filtered 
and suitably diluted. The drug content was estimated spectrometrically.

In vitro dissolution studies

In vitro dissolution studies were carried out in $900 \mathrm{ml}$ phosphate buffer PH 6.8 using USP dissolution testing apparatus (Model TDT 08L, Electro lab, Mumbai India) with a rotating stirrer speed at $100 \mathrm{rpm}$, and temperature of dissolution medium maintained at $37 \pm 0.5^{\circ} \mathrm{C} .5 \mathrm{ml}$ of aliquots were withdrawn at regular intervals, filtered and same amount of fresh dissolution medium was replaced at the same temperature. The filtered solutions were analyzed by using (Shimadzu, Japan) UV- spectrophotometer at $271 \mathrm{~nm}$.

\section{Results and Discussions}

Table 2. Ir spectral values for physical mixture of drug and excipients.

\begin{tabular}{|c|c|c|c|c|}
\hline \multirow{3}{*}{ Functional group } & \multicolumn{4}{|c|}{ Observed wave number $\left(\mathrm{cm}^{-1}\right)$} \\
\hline & \multirow{2}{*}{ Tramadol hydrochloride } & \multicolumn{3}{|c|}{ Physical mixture of Tramadol hydrochloride with } \\
\hline & & HPMC & $\mathrm{NaCMC}$ & MC \\
\hline O-H stretching & 3305.25 & 3305.83 & 3305.61 & 3305.77 \\
\hline $\mathrm{C}-\mathrm{O}$ stretching of ethers & 1045.70 & 1045.65 & 1045.28 & 1045.63 \\
\hline $\mathrm{C}-\mathrm{H}$ stretching of alkyl group & 2930.45 & 2930.29 & 2929.90 & 2930.25 \\
\hline C-H deformation of alkyl group & 1480.42 & 1479.98 & 1480.36 & 1479.82 \\
\hline$C-C$ formotioning & 1607.27 & 1607.30 & 1607.26 & 1607.39 \\
\hline Aromatic mono substituted C-H deformation & 702.69 & 702.83 & 702.78 & 702.79 \\
\hline C-H stretching of cycloalkanes & 2930.45 & 2930.29 & 2929.90 & 2930.25 \\
\hline
\end{tabular}

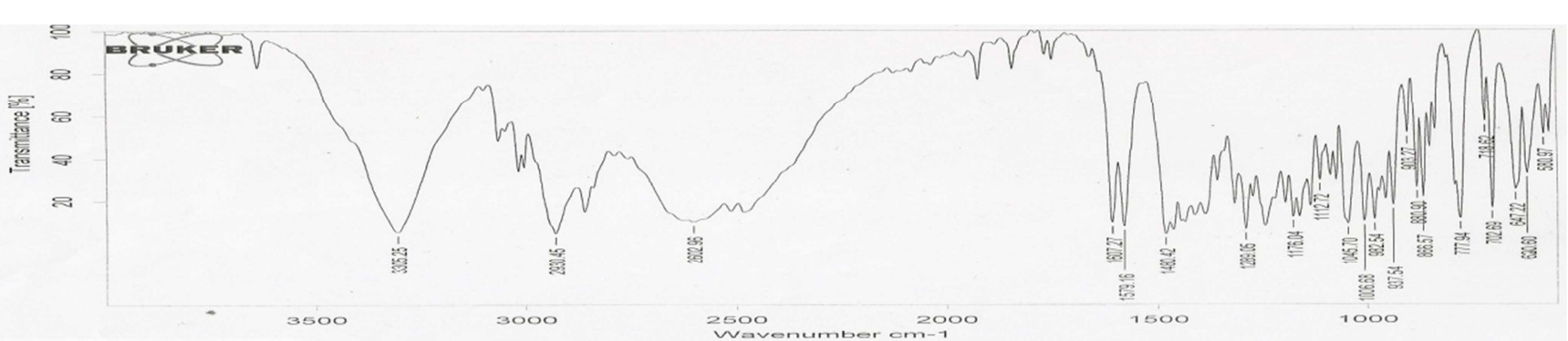

Figure 1. Ir spectra of tramadol hydrochloride.

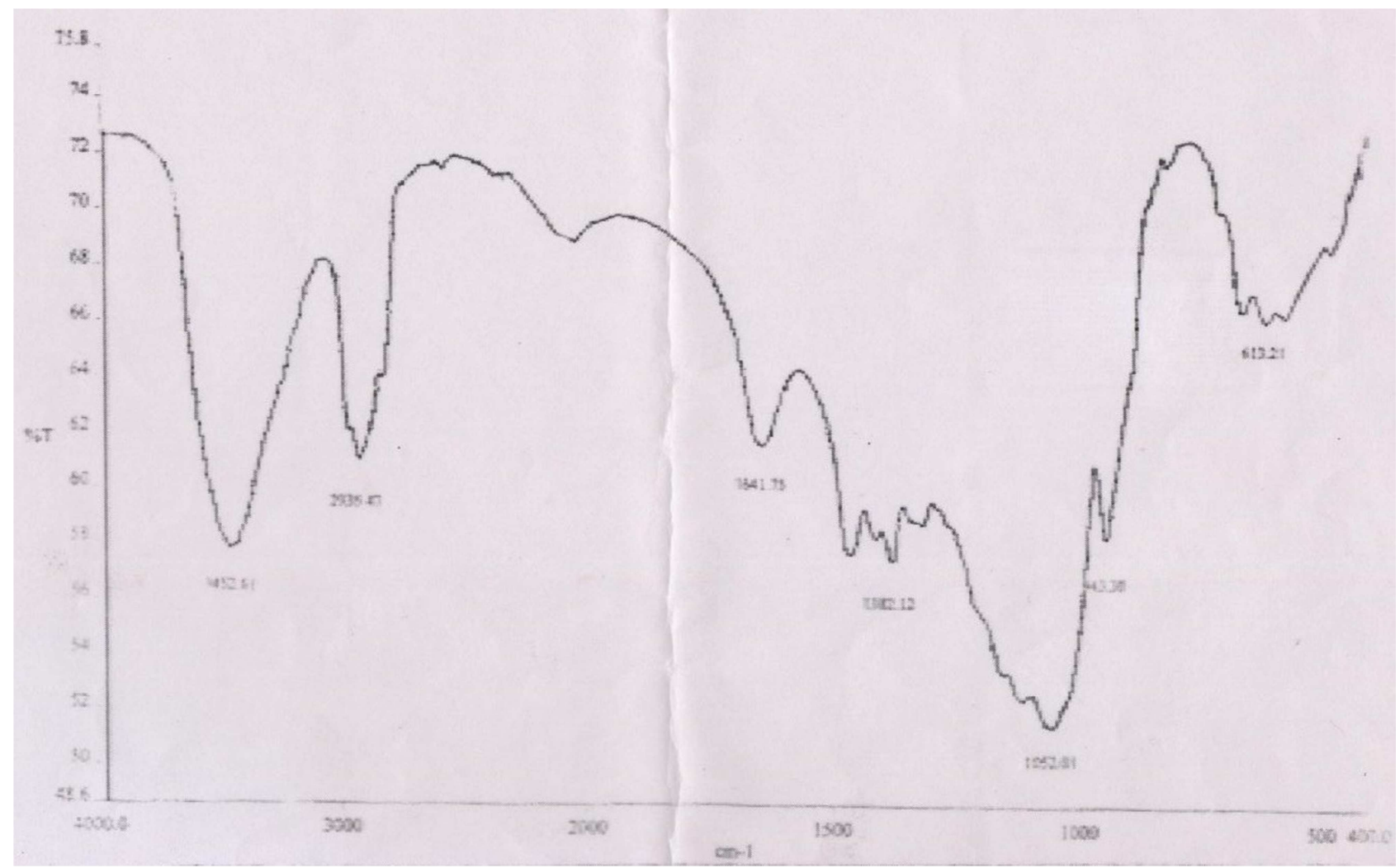

Figure 2. Ir spectra of HPMC. 


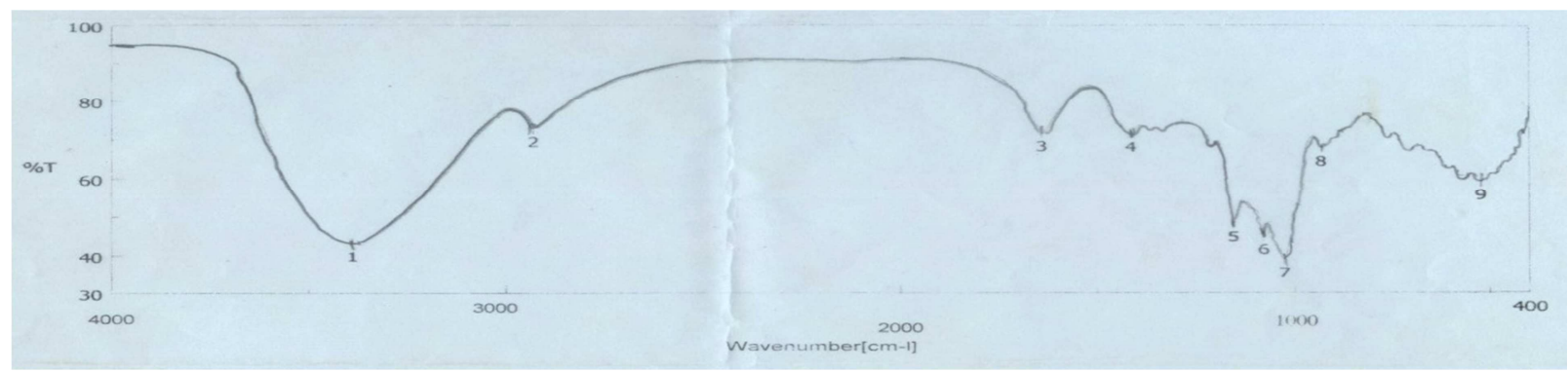

Figure 3. Ir spectra of $\mathrm{NaCMC}$.

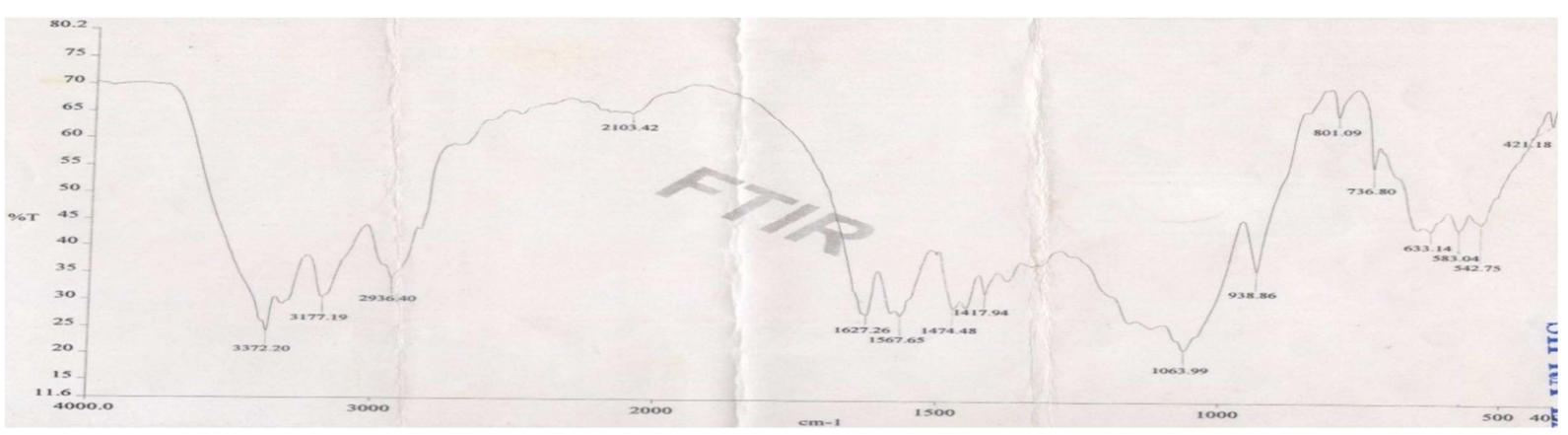

Figure 4. Ir spectra of methyl cellulose.

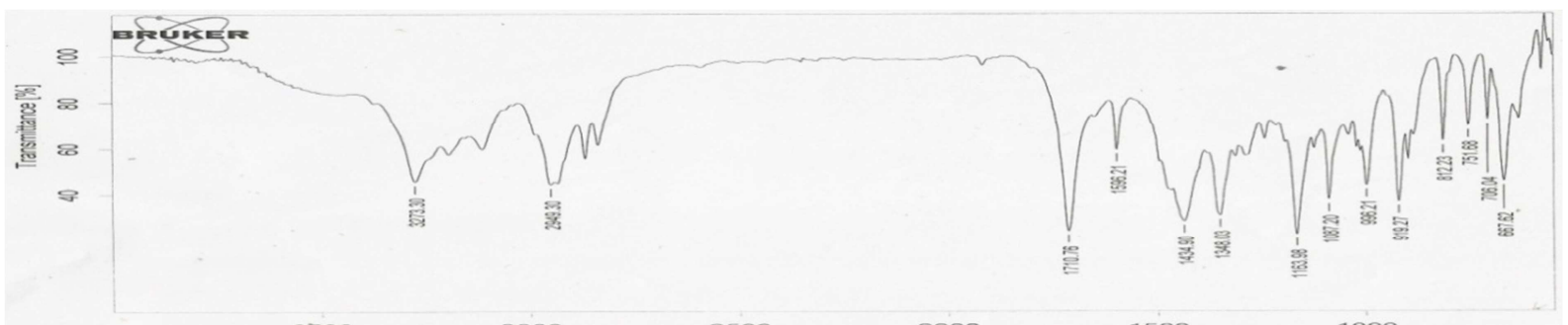

Figure 5. Ir spectra of physical mixture of trmadol hydrochloride $+H P M C$.

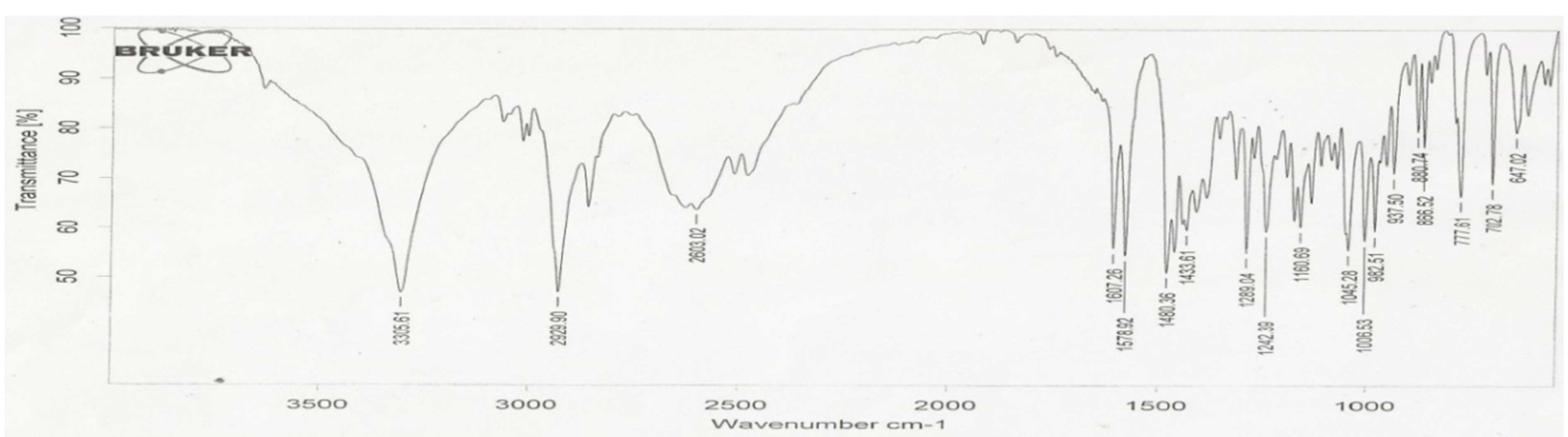

Figure 6. Ir spectra of physical mixture of trmadol hydrochloride $+\mathrm{NaCMC}$.

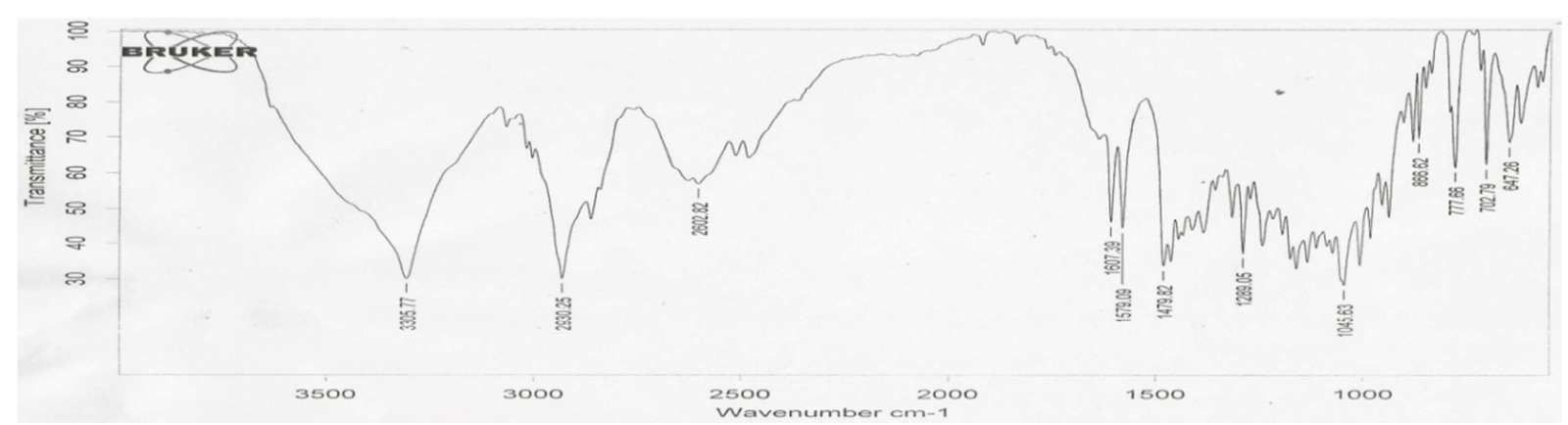

Figure 7. Ir spectra of physical mixture of trmadol hydrochloride + methyl cellulose. 
Patient compliance is one of the important aspect for administration of drugs and attractive, taste masking, ease of administration are also needed to the patient. In the present study Tramadol Hydrochloride sweetened lozenges were designed and evaluated for effective treatment of pain in children. Drug-excipients compatability studies i. e Tramadol Hydrochloride and polymers (HPMC, NaCMC, and $\mathrm{MC}$ ) compatibility studies were conducted by using FTIR spectral studies. The results of IR spectra of Tramadol Hydrochloride and polymers (HPMC, NaCMC, $\mathrm{MC})$ individually and the physical mixture of Tramadol Hydrochloride and polymers (HPMC, NaCMC, MC) suggested that the characteristic peaks observed in Tramadol Hydrochloride pure samples were mostly identical with the peaks in the physical mixture of Tramadol Hydrochloride and polymers (HPMC, NaCMC, MC) adhering within their ranges without changes in the functionalities indicating their compatibility results given in table no 2 and fig 1, 2, 3, 4, 5, 6, 7 and 8. For formulation development drug excipient interactions play an important role so formulations were subjected to compatability studies, so finally it was observed that there was no additional peaks in drug- polymer mixture and hence formulations were developed with the selected polymers in the second stage of present investigations.

\subsection{Studies on Tramadol Hydrochloride Hard Lozenges Formulated with Malt Syrup}

Studies on Tramadol hydrochloride hard lozenges formulated with HPMC 3000cps.

The prepared tramdol hydrochloride hard lozenges evaluated forphysico-chemical parameters like hardness, friability, content uniformity, weight variation, thickness and drug content, results reported in the table no 3 .
The Thickness of the formulations F1, F2, F3 was14.4 \pm $0.43,14.5 \pm 0.22,14.6 \pm 0.35, \%$ weight variation was found to be $3.75 \pm 0.42,3.48 \pm 0.33,3.57 \pm 0.47$, hardness of the formulations were $16.5 \pm 0.26,16.8 \pm 0.13,16.7 \pm 0.11$ $\mathrm{kg} / \mathrm{cm}^{2}, \%$ Friability was $0.96 \pm 0.26,0.93 \pm 0.43,0.95 \pm$ $0.21 \%$ and $\%$ drug content was found to be $97.6 \pm 0.35,93.7$ $\pm 0.27,92.7 \pm 0.31$.

In vitro drug release data for formulations were recorded in table no 4 . The \% drug release for F1, F2, F3 was93.2, 94.6, 98.8 , observed at the end of 25, 25 and 30mins. The \% Drug release profiles of these formulations depicted in fig 8 and drug release data fitted into various kinetic equations, drug release mechanism exhibits first order kinetics depicted in fig 9 and results given in table no 4 .

\subsection{Studies on Tramadol Hydrochloride Hard Lozenges Formulated with NaCMC}

The prepared tramdol hydrochloride hard lozenges evaluated forphysico-chemical parameters like hardness, friability, content uniformity, weight variation, thickness and drug content, results reported in the table no 3.

The Thickness of the formulations F4, F5, F6 was $14.6 \pm$ $0.17,14.7 \pm 0.21,14.5 \pm 0.42, \%$ weight variation was found to be $2.47 \pm 0.28,3.99 \pm 0.26,4.92 \pm 0.24$, hardness of the formulations were $16.9 \pm 0.37,16.6 \pm 0.14,16.5 \pm$ $0.31 \mathrm{~kg} / \mathrm{cm}^{2} \%$ friability was found to be $0.95 \pm 0.34,0.97$ $\pm 0.13,0.93 \pm 0.42 \%$ and $\%$ drug content was found to be $96.8 \pm 0.15,97.6 \pm 0.13,98.9 \pm 0.37 \%$. The $\%$ drug release for F4, F5, F6 was 94.7, 96.7, 95.2, observed at the end of 15,20 and 20 mins. The $\%$ drug release profiles of these formulations depicted in fig 10 and drug release data fitted into various kinetic equations, drug release mechanism exhibits first order kinetics depicted in fig 11 and results given in table no 4.

Table 3. Evaluation of tramadol hydrochloride hard lozenges using malt syrup as base.

\begin{tabular}{|c|c|c|c|c|c|}
\hline Formulations & Thickness (Cm) & Weight Variation (\%) & Hardness $\left(\mathrm{kg} / \mathrm{cm}^{2}\right)$ & Friability (\%) & Drug content (\%) \\
\hline F1 & $14.4 \pm 0.43$ & $3.75 \pm 0.42$ & $16.5 \pm 0.26$ & $0.96 \pm 0.26$ & $97.6 \pm 0.35$ \\
\hline $\mathrm{F} 2$ & $14.5 \pm 0.22$ & $3.48 \pm 0.33$ & $16.8 \pm 0.13$ & $0.93 \pm 0.43$ & $93.7 \pm 0.27$ \\
\hline F3 & $14.6 \pm 0.35$ & $3.57 \pm 0.47$ & $16.7 \pm 0.11$ & $0.95 \pm 0.21$ & $92.7 \pm 0.31$ \\
\hline $\mathrm{F} 4$ & $14.6 \pm 0.17$ & $2.47 \pm 0.28$ & $16.9 \pm 0.37$ & $0.95 \pm 0.34$ & $96.8 \pm 0.15$ \\
\hline F5 & $14.7 \pm 0.21$ & $3.99 \pm 0.26$ & $16.6 \pm 0.14$ & $0.97 \pm 0.13$ & $97.6 \pm 0.13$ \\
\hline F6 & $14.5 \pm 0.42$ & $4.92 \pm 0.24$ & $16.5 \pm 0.31$ & $0.93 \pm 0.42$ & $98.9 \pm 0.37$ \\
\hline F7 & $14.5 \pm 0.33$ & $2.85 \pm 0.13$ & $16.9 \pm 0.27$ & $0.91 \pm 0.24$ & $95.7 \pm 0.32$ \\
\hline F9 & $14.7 \pm 0.41$ & $3.43 \pm 0.46$ & $16.3 \pm 0.46$ & $0.94 \pm 0.41$ & $96.7 \pm 0.26$ \\
\hline
\end{tabular}

Table 4. In-vitro drug release kinetics of tramadol HCL hard lozenges using malt syrup as base.

\begin{tabular}{|c|c|c|c|c|c|}
\hline \multirow{2}{*}{ Formulation } & \multicolumn{2}{|c|}{ Correlation coefficient values } & \multirow{2}{*}{$\begin{array}{l}\text { Release rate constant } \\
(\mathrm{K})\left(\mathrm{min}^{-1}\right)\end{array}$} & \multirow{2}{*}{$\mathbf{T}_{50(\min )}$} & \multirow{2}{*}{$\mathbf{T}_{90(\min )}$} \\
\hline & Zero order & First order & & & \\
\hline F1 & 0.8976 & 0.9922 & 0.145 & 4.77 & 15.88 \\
\hline F2 & 0.9023 & 0.9876 & 0.131 & 5.29 & 17.58 \\
\hline F3 & 0.8934 & 0.9854 & 0.129 & 5.37 & 17.85 \\
\hline $\mathrm{F} 4$ & 0.9043 & 0.9871 & 0.149 & 4.65 & 15.45 \\
\hline F5 & 0.8993 & 0.9652 & 0.141 & 4.91 & 1.34 \\
\hline F6 & 0.8234 & 0.9143 & 0.136 & 5.09 & 16.93 \\
\hline F7 & 0.9324 & 0.9456 & 0.147 & 4.71 & 15.66 \\
\hline F8 & 0.9024 & 0.9567 & 0.133 & 5.21 & 17.31 \\
\hline F9 & 0.8973 & 0.9723 & 0.128 & 5.41 & 17.99 \\
\hline
\end{tabular}




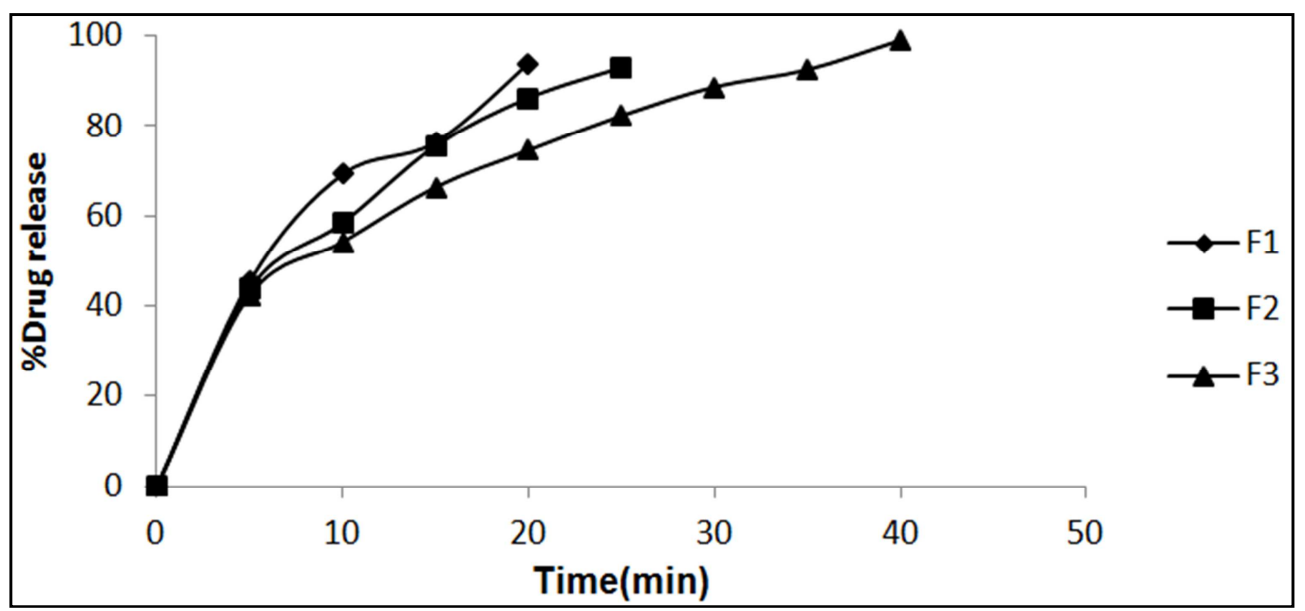

Figure 8. Invitro dissolution \% drug release profiles of tramadol hydrochloride hard lozenges formulated with HPMC.

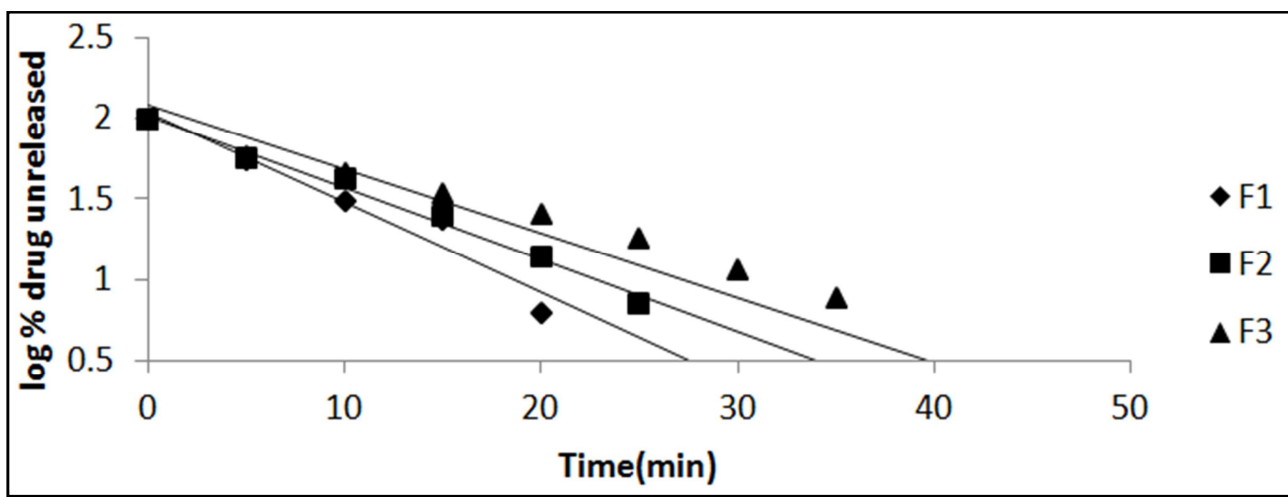

Figure 9. Frist order plots of tramadol hydrochloride hard lozenges formulated with NACMC.

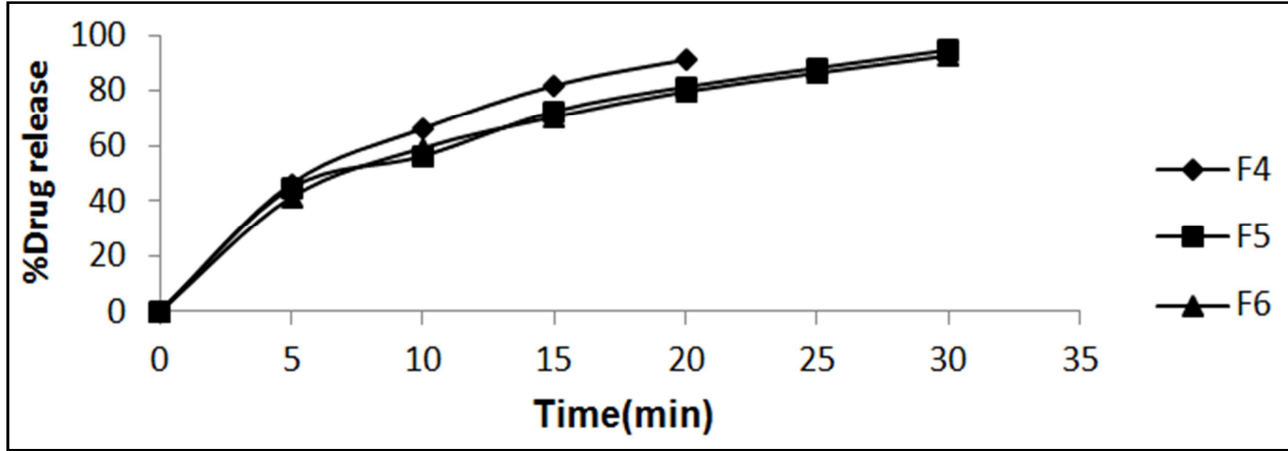

Figure 10. Invitro dissolution \%drug release profiles of tramadol hydrochloride hard lozenges formulated with NACMC.

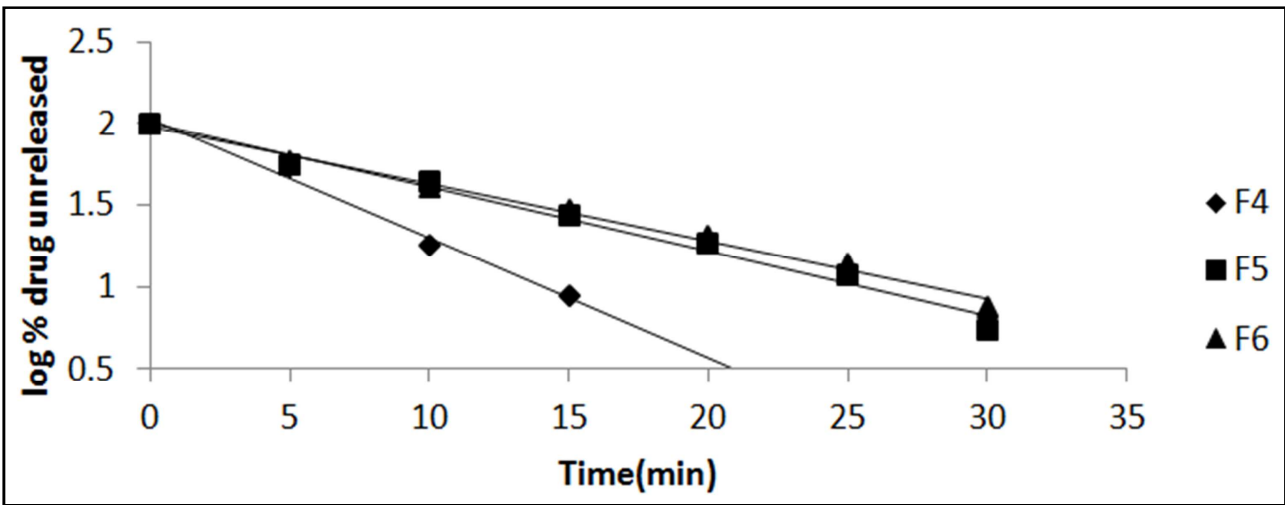

Figure 11. Frist order plots of tramadol hydrochloride hard lozenges formulated with NACMC 


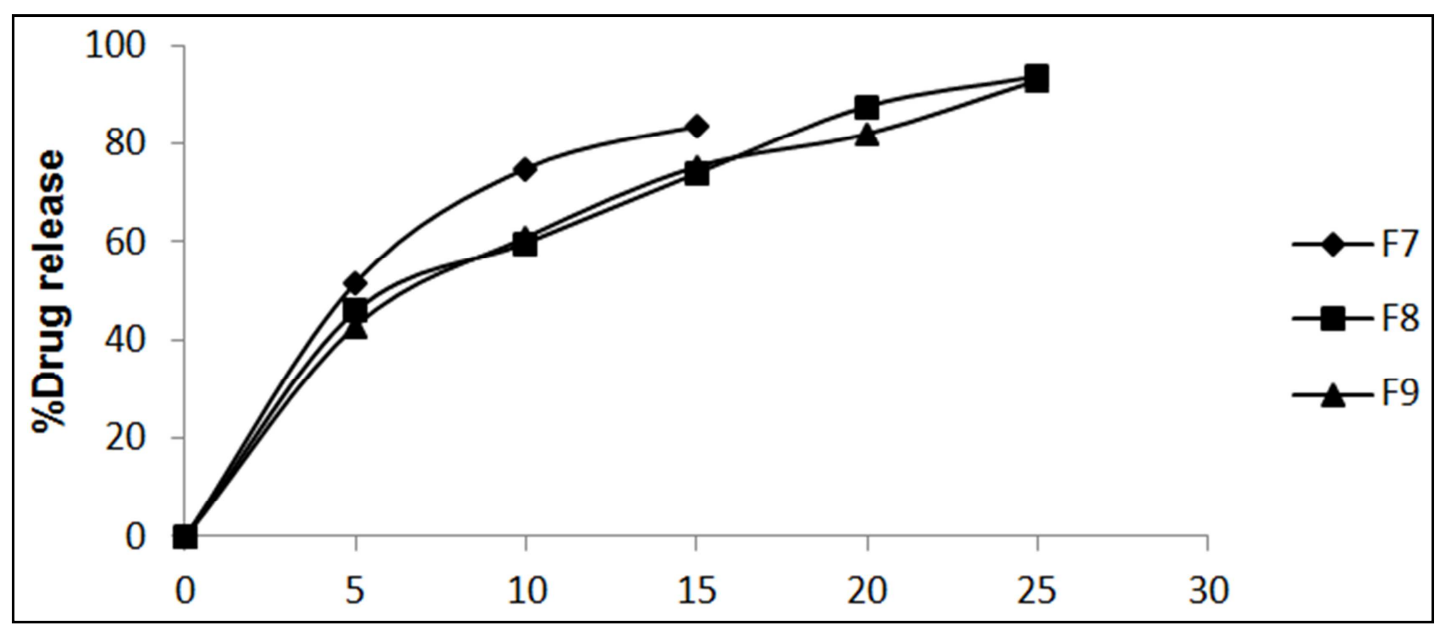

Figure 12. Invitro dissolution \%drug release profiles of tramadol hydrochloride hard lozenges formulated with MC

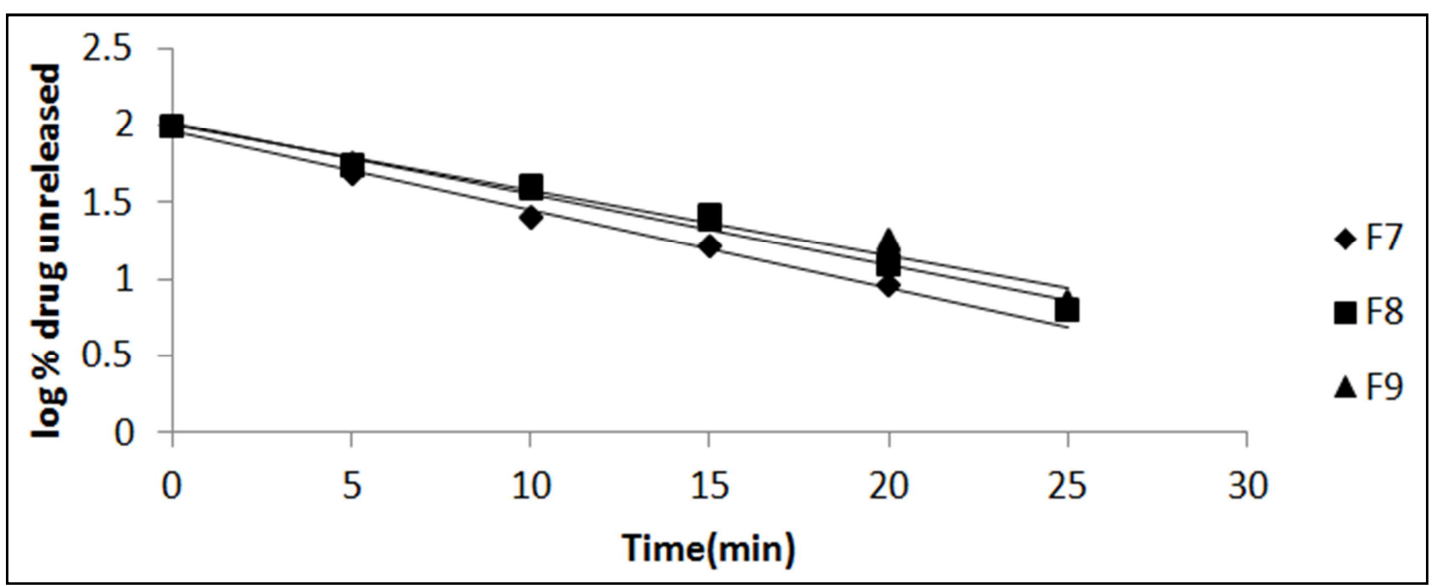

Figure 13. Frist order plotsof tramadol hydrochloride hard lozenges formulated with MC.

\subsection{Studies on Tramadol Hydrochloride Hard Lozenges Formulated with $M C$}

The prepared tramdol hydrochloride hard lozenges evaluated forphysico-chemical parameters like hardness, friability, content uniformity, weight variation, thickness and drug content, results reported in the table no 3The Thickness of the formulations F7, F8, F9 is $14.5 \pm 0.33$, $14.6 \pm 0.25,14.7 \pm 0.41$. The $\%$ weight variation was found to be $2.85 \pm 0.13,3.67 \pm 0.34,3.43 \pm 0.46$, hardness of the formulations were $16.9 \pm 0.27,16.7 \pm 0.41,16.3 \pm 0.46 . \%$ friability was found to be $0.91 \pm 0.24,0.96 \pm 0.36,0.94 \pm$ $0.41 \%$ and $\%$ drug content was found to be $95.7 \pm 0.32$, $97.5 \pm 0.28$, and $96.7 \pm 0.26 \%$. The $\%$ drug release for F7, F8, F9 are 92, 93.1, 95.7 observed at the end of 15, 15 and $20 \mathrm{~min}$. The \% Drug release profiles of these formulations depicted in fig 12 and drug release data fitted into various kinetic equations, drug release mechanism exhibits first order kinetics depicted in fig 13 and results given in table no 4.

Among all the formulations formulated with malt syrup and HPMC 3000 cps F3 was given satisfactory results because of its viscosity and good binding property of malt syrup when compared with the other bases such as corn syrup and liquid glucose.

In the formulations mint flavour such as menthol are preferred in a slow dissolving lozenges, it provides a desirable soothing effect and by substantially micronizing or reducoing the particle size of antacid salts were incorporated to improve the organoleptic properties including mouth feel and taste of the product. It yields a product exhibiting a dense, non gritty and smooth texture for improved mouth feel.

In order to enhance the flow of saliva an acidulent is employed in the dry mouth lozenges. These are generally present in amount ranging from about 0.1 to $0.5 \%$ by weight of lozenges.

This type of vehicle allows the production of pleasent tasting product for the delivery of unpleasant tasting of drugs. The unique proportion of this vehicle are preserved in the final form while containg active ingredients which modifies the stimulatory taste receptors in the orl cavity to the extents of suppressing bitterness and other forms of unpleasant taste imported by actives.

Lozenges having wide advantages such as increase in bioavailability, reduce the gastric irritation, and to avoid the first pass metabolism. They can be prepared by molding (gelatin and / or fused sucrose or sorbitol base) or by compression of sugar- based tablets. Molded lozenges are 
sometimes referred to as troches. Molded lozenges have a softer texture because they contain a high percentage of sugar or a combination of a gelatin and sugar.

The maximum amount of drug released observed from the formulations formulated with sodium CMC, HPMC, MC at the end of 30 mins due to the chemical structure and gelling of swell able layer, while penetration of the saliva/media and also malt syrupwas responsible for the release of drug. This novel product which is recognized to be unique to its delivery system and made easy, conveint to take by the consumer for fast result when compared to the tablets/liquid preparations.

These lozenges are experiencing renewed popularity as a means of delivering different drug products, especially for patients who cannot swallow solid oral dosage forms and also used for it was designed for release of 30 mins for the treatment of pain in childreans.

\section{Conclusion}

From the present study it was suggested that corn syrup based tramadol hydrochloride wiil be ideal dosage forms for the treatment of pain to the paediatrics. By incorporation of synthetic polymers yields good results and release the drugs for a prolonged period of 30 mins.

Lozenges areintented to slowly dissolve in the mouth over a relatively long period of time. Eg; usually about 2-15 mins or more as needed. The taste bud and olfactory sences are able to detect even the slightest bittetness of unpleasant mouth feel and taste during such a long residence time in the mouth represents a substantial challenges it is desirable to provide a palatable dosage form of tramadol hydrochloride hard lozenges.

\section{References}

[1] N. K. Jain. "Mucoadhesive Drug Delivery". Controlled and Novel Drug Delivery. Edition-5, CBS Publishers and Distributors, New Delhi, 2005; 353-76.
[2] Harsh Mohan. "The oral cavity and salivary Glands". Text book of Pathology. 4th edn, Jaypee Brothers, Medical Publishers (P) Ltd, New Delhi, 2000;494-96.

[3] Larry L Augsburger, Stephen W Hoag. "Formulation of Specialty Tablets for Slow Oral Dissolution". Loyd V. Pharmaceutical dosage forms: tablets: Rational design and formulation. $3^{\text {rd }}$ Edition, Allen University of Oklahoma college of pharmacy, Oklahoma City, Oklahoma, U.S.A.(2),2009; 361-81.4.

[4] Gilbert S. Banker, Neil R. Anderson. Tablets Leon Lachman Herbert A. Liberiman. Theory and Practice of Industrial pharmacy edition3rd 1987; 331.

[5] Gilbert S. Banker, Neil R. Anderson. Tablets Leon Lachman Herbert A. Liberiman. Theory and Practice of Industrial pharmacy edition3rd 1987; 331.

[6] Ansel. "Solid modified release drug delivery Ssystems". Ansel's pharmaceutical dosage form and drug delivery systems $9^{\text {th }}$ edition, 2002; P. NO 252.

[7] Shishu, Ashima Bhatti, Tejbir Singh. "Preparation of tablets rapidly disintegrating in saliva containing bitter taste-masked granules by compression method". Indian Journal of Pharmaceutical Sciences 60(1), 2007; 80-4.

[8] Loyd V Allen. "Troches and lozenges". Current and practical compounding information for the pharmacist 4(2), 1998; p.no213-34.

[9] Gibbs KP, Portlock JC. "Clinical Pharmacy and therapeutics". 2ndEdn, Walker Edwards, Scotland, 1999; 347-67.

[10] Purushotham RK, Shivappa NN, Zakaullah S, Arshiya SA, Ashok KC, Anand C. "Mediacted lozenges of ketoconazole for pediatric oral thrush patients". Int J Inst Pharm LifeSc 1(3), $2011 ; 25-33$.

[11] Rajesh K, Mahalaxmi R, Deepak K. "Investigating the suitability of isomalt and liquid glucose as sugar substitute in the formulation of salbutamol sulfate hard candy lozenges". J Chem and Pharm Res 3(4), 2011; 69-75. 